\title{
Addendum: 3' UTR seed matches, but not overall identity, are associated with RNAi off-targets
}

Amanda Birmingham, Emily M Anderson, Angela Reynolds, Diane Ilsley-Tyree, Devin Leake, Yuriy Fedorov, Scott Baskerville, Elena Maksimova, Kathryn Robinson, Jon Karpilow, William S Marshall \& Anastasia Khvorova

Nat. Methods 3, 199-204 (2006).

\section{Corrigendum: GFP expression in muscle cells impairs actin-myosin} interactions: implications for cell therapy

Onnik Agbulut, Catherine Coirault, Nicolas Niederländer, Alexis Huet, Patrick Vicart, Albert Hagège, Michel Puceat \& Philippe Menasché

Nat. Methods 3, 331 (2006).

The correct web address for the Gene Vector Production Network is http://www.genethon.fr. 